\title{
Use of Magnetocapsules for In Vivo Visualization and Enhanced Survival of Xenogeneic HepG2 Cell Transplants
}

\author{
Thomas W. Link, $* \dagger \S$ Dian R. Arifin,*§ Christopher M. Long, $\dagger$ Piotr Walczak, *§ Naser Muja,*§ \\ Aravind Arepally,,$\# * *$ and Jeff W.M. Bulte* $\uparrow \ddagger \S$ \\ *Russell H. Morgan Department of Radiology and Radiological Science, Division of MR Research, \\ The Johns Hopkins University School of Medicine, Baltimore, MD, USA \\ $\dagger$ Department of Biomedical Engineering, The Johns Hopkins University School of Medicine, Baltimore, MD, USA \\ $\$$ Department of Chemical and Biomolecular Engineering, The Johns Hopkins University School of Medicine, Baltimore, MD, USA \\ §Cellular Imaging Section and Vascular Biology Program, Institute for Cell Engineering, \\ The Johns Hopkins University School of Medicine, Baltimore, MD, USA \\ IDivision of Interventional Radiology, Piedmont Hospital, Atlanta, GA, USA \\ \#Department of Radiology, The Johns Hopkins Medical Institutes, Baltimore, MD, USA \\ **Department of Surgery, The Johns Hopkins Medical Institutes, Baltimore, MD, USA
}

\begin{abstract}
Hepatocyte transplantation is currently being considered as a new paradigm for treatment of fulminant liver failure. Xeno- and allotransplantation studies have shown considerable success, but the long-term survival and immunorejection of engrafted cells need to be further evaluated. Using novel alginate-protamine sulfate-alginate microcapsules, we have coencapsulated luciferase-expressing HepG2 human hepatocytes with superparamagnetic iron oxide nanoparticles to create magnetocapsules that are visible on MRI as discrete hypointensities. Magnetoencapsulated cells survive and secrete albumin for at least 5 weeks in vitro. When transplanted intraperitoneally in immunocompetent mice, encapsulated hepatocytes survive for at least 4 weeks as determined using bioluminescent imaging, which is in stark contrast to naked, unencapsulated hepatocytes that died within several days after transplantation. However, in vivo human albumin secretion did not follow the time course of magnetoencapsulated cell survival, with plasma levels returning to baseline values already at 1 week post-transplantation. The present results demonstrate that encapsulation can dramatically prolong survival of xenotransplanted hepatocytes, leading to sustained albumin secretion with a duration that may be long enough for use as a temporary therapeutic bridge to liver transplantation.
\end{abstract}

Key words: Cell transplantation; Fulminant liver failure; Magnetic resonance imaging; Iron nanoparticle contrast agent; Bioluminescent imaging

\section{INTRODUCTION}

Fulminant liver failure (FLF) is characterized as the appearance of a sudden, severe liver injury accompanied by hepatic encephalopathy and impaired protein synthesis in previously healthy individuals. There are approximately 2,000 reported cases of FLF in the United States yearly, comprising $0.1 \%$ of all causes of deaths (13). Acute liver failure (ALF) resembles FLF as a disease, except that hepatic encephalopathy develops after an illness duration of 1-12 weeks. Like FLF, there are also around 2,000 cases reported annually in the United States (17). Primary causes of FLF and ALF include viral hepatitis and drug- or alcohol-induced liver damage.
Liver allotransplantation is the only effective therapeutic solution for patients with FLF and ALF. However, challenges associated with procurement, allocation, and distribution of suitable immunocompatible organs have led to prolonged waiting times and high mortality among recipients on the waiting list (9). Even with the development of newer surgical techniques, the mortality rate of recipients on the waiting list remains around $9 \%$ and may be even higher for the juvenile population (26). It is estimated that 2,200 patients in the United States die each year while awaiting liver transplantation (36).

Artificial and bioartificial hepatic support systems have been proposed as a temporary "bridge" therapy to provide palliative care and sustain patient survival until

Received February 29, 2012; final acceptance July 27, 2012. Online prepub date: August 27, 2012.

Address correspondence to Jeff W.M. Bulte, Ph.D., Russell H. Morgan Department of Radiology and Radiological Science, Division of MR Research, The Johns Hopkins University School of Medicine, 217 Traylor Building, 720 Rutland Avenue, Baltimore, MD 21205, USA. Tel.: +1 443287 0996; Fax: +1 443287 6730; E-mail: jwmbulte@ mri.jhu.edu 
a suitable liver is available for transplantation. Such systems function to remove waste metabolites and toxins, synthesize metabolites and enzymes, and reverse hepatic inflammatory processes. Examples of artificial devices include BioLogic-DT and the Molecular Adsorbent Recirculating System, which combine hemodialysis with adsorption using charcoal or albumin, and the bioartificial liver (BAL) device and extracorporeal liver assist device (ELAD), which operate by processing the patients blood through a bioreactor containing live hepatocytes (20). According to a meta-analysis of 11 randomized trials, neither of these support systems significantly reduced mortality as compared to standard medical procedures for liver failure (43).

Transplantation of xenogeneic hepatocytes provides an alternative to liver transplantation for $\operatorname{FLF}(12,14)$, as well as an alternative to artificial and bioartificial support systems as a bridge to transplantation $(11,32)$. For example, isolated, cryopreserved human hepatocytes have been delivered to the spleen of patients with grade IV encephalopathy and were compared to controls who received standard medical therapy (36). While all control patients died within 3 days, the hepatocyte-treated patients maintained normal cerebral perfusion and cardiac stability, with blood ammonia decreasing to normal levels. Successful, life-saving transplantation was achieved in three of the five patients who were still alive 20 months later.

Microencapsulation, which involves surrounding cells by a semipermeable alginate membrane, may be used to alleviate the need for immunosuppressive therapy in cell transplant studies (25). This approach has primarily been applied for microencapsulated pancreatic islet cells in preclinical $(25,40)$ and clinical $(33,41)$ treatment of type I diabetes. As for the case of FLF, naked and microencapsulated immortalized human hepatocytes have been injected into the peritoneal cavity of mice induced with FLF. Survival was increased from $23 \%$ to $55 \%$, and histopathology revealed that encapsulated hepatocytes were viable up to 2 weeks post-transplantation (21).

While preliminary studies demonstrate the proof of concept for microencapsulated hepatocyte treatment as an intermediate palliative option preceding identification and transplantation a matching donor organ, additional research is required to monitor the long-term efficacy of the transplanted cells. Serial noninvasive imaging that could correlate the transplantation site with the anatomical site of engraftment and long-term cell viability is necessary to better understand the fate of the hepatocytes after transplantation and is considered to be critical for clinical implementation (28).

In this study, we describe the use of magnetic resonance imaging (MRI)-visible magnetocapsules (MCs) $(4,19,23)$ that enable in vivo visualization of the engraftment of xenogeneic HepG2 human hepatocytes in mice. In addition, we performed serial bioluminescent imaging (BLI) to assess survival of luciferase-transfected HepG2 cells over a period of up to 5 weeks after transplantation into immunocompetent mice. We report here that, as compared to transplants of naked, unencapsulated cells, encapsulated human hepatocytes survive much longer with sustained albumin production in vivo.

\section{MATERIALS AND METHODS}

\section{Cell Culture and Luciferase Transduction}

Hep2G human hepatocytes, a perpetual cell line derived from the liver tissue of a 15-year-old Caucasian American male with a well-differentiated hepatocellular carcinoma, were obtained from American Type Culture Collection (ATCC \#HB-065, Rockville, MD). Cells were grown in T-75 flasks in Eagle's minimum essential media (EMEM) supplemented with $10 \%$ fetal bovine serum (FBS, Life/Technologies/Gibco BRL, Grand Island, NY) and $5 \%$ penicillin/streptomycin. This medium was used in all experiments, unless otherwise specified. Medium was changed once every 3 days, and cells were passaged at $80 \%$ confluency. For lentiviral $L u c$ transduction, cells were plated into six-well plates at $80 \%$ confluency. Packaged lentivector (pLenti4-CMV-fLuc2) was added at $250 \mu \mathrm{l} / \mathrm{ml}$ media. The amount of virus was calculated to achieve a multiplicity of infection (MOI) of 10. Polybren was added at $6 \mu \mathrm{g} / \mathrm{ml}$ and allowed to incubate overnight to enhance transduction efficiency. Medium was then changed, and after $24 \mathrm{~h}$ cells were transferred back to T-75 flasks for further expansion.

\section{Magnetoencapsulation}

Magnetocapsule synthesis was performed as described previously $(4,5)$. Briefly, alginate (NovaMatrix, Sandvika, Norway) was suspended in sterile $0.9 \%$ saline and mixed with the appropriate amount of Feride ${ }^{\circledR}$ [superparamagnetic iron oxide (SPIO) particles; AMAG Pharmaceuticals, Lexington, MA] to produce a $2 \% \mathrm{w} / \mathrm{w}$ alginate and $20 \%$ v/v Feridex ${ }^{\circledR}$ solution. $1.5 \times 10^{7}$ Luc human hepatocytes were suspended in this mixture and loaded into a 1-ml syringe. The syringe was loaded into a custommade encapsulation system consisting of a syringe pump (Harvard Apparatus, Holliston, MA) and a high-voltage power supply (Spellman, Hauppauge, NY) wired to the needle of the syringe. The cell-alginate mixture was dispensed into a Petri dish containing $100 \mathrm{mM} \mathrm{CaCl}_{2}$ and $10 \mathrm{mM}$ 4-(2-hydroxyethyl)-1-piperazineethanesulfonic acid (HEPES) at a rate of $0.2 \mathrm{ml} / \mathrm{min}$. This $\mathrm{CaCl}_{2}$ bath was grounded so that an electrostatic force draws droplets from the tip of the needle into the bath. These settings resulted in the production of approximately 12,000 magnetocapsules (MCs) measuring $500 \mu \mathrm{m}$ in diameter, with each MC containing around 1,000 cells. MCs were 
collected and washed three times with $0.9 \%$ saline containing $10 \mathrm{mM}$ HEPES and then suspended in a $0.05 \%$ protamine sulfate (APP Pharmaceuticals, Schaumburg, IL) solution for $5 \mathrm{~min}$. After three more washes, the MCs were suspended in a secondary $0.15 \%$ alginate solution for 5 min more, followed by a final three-step saline wash.

\section{In Vitro Characterization}

After saline washing, capsules were visualized using an inverted light microscope (Olympus IX71, Center Valley, PA). Magnetoencapsulated and naked hepatocytes were assessed and compared for human albumin production and survival in vitro. Naked hepatocytes were plated into 12-well plates at a density of $10^{4}$ cells per well. Immediately after magnetoencapsulation, MCs were divided up into wells in six-well plates so that there were $100 \mathrm{MCs}$ with $5 \mathrm{ml}$ of media in each well. For cell viability/proliferation assessment, luciferin $(150 \mu \mathrm{g} / \mathrm{ml})$ was added every 3-4 days, and after 5-min incubation, BLI was performed using an IVIS 200 optical imaging device (Caliper Life Sciences, Hanover, MD) with 10-sec exposure time. Following each imaging session, naked cells and encapsulated cells were washed to remove luciferase substrate and then replated with fresh media.

For assessment of human albumin secretion, $1 \mathrm{ml}$ of cell culture medium was removed every 3-4 days. Collected samples were stored at $-80^{\circ} \mathrm{C}$. Cells were then washed and replated with fresh media. At the end of the testing period, frozen samples were thawed and assayed for human albumin using a human albumin ELISA kit (AssayPro, St. Charles, MO). Medium containing FBS but without cells was included as negative control. According to the manufacturer, cross-reactivity with bovine and mouse albumin is $<0.02 \%$ and $<0.1 \%$, respectively.

\section{Transplantation and Functional Assessment of Magnetocapsulated HepG2 Hepatocyes}

Mouse studies were approved by our institutional animal care and use committee. White FVB female mice, 6-8 weeks old, were kept in cages with food ad libitum. Magnetoencapsulated and naked (i.e., unencapsulated) cells were suspended in $1.0 \mathrm{ml}$ of sterile $0.9 \%$ saline and injected intraperitoneally under $1.5 \%$ general isoflurane anesthesia using a $20-\mathrm{G}$ needle. Mice were injected with $3,000(n=8)$ or $6,000(n=8)$ MCs (corresponding to $3 \times 10^{6}$ and $6 \times 10^{6}$ cells, respectively) and with $3.75 \times 10^{6}$ $(n=8)$ or $7.5 \times 10^{6}(n=8)$ naked cells. Blood samples $(150-200 \mu \mathrm{l})$ were collected from the tail vein at days $1,3,7,10,14,21$, and 28 days after transplantation. Baseline (pretransplantation) blood samples were also obtained. Blood samples were centrifuged at 12,000 rpm for $5 \mathrm{~min}$, and plasma was collected and then stored at $-80^{\circ} \mathrm{C}$. Human albumin secretion was determined using the same AssayPro ELISA kit.

\section{Noninvasive Imaging of Cell Survival} and Magnetocapsule Engraftment

Serial noninvasive imaging experiments were performed under general $1.5 \%$ isoflurane anesthesia. For BLI, at each time point mice were injected intraperitoneally with $150 \mathrm{mg} / \mathrm{kg}$ luciferin and imaged $15 \mathrm{~min}$ later using an IVIS 200 optical imaging device with a 10-s exposure time. Image analysis was done using LivingImage software. Regions of interest were drawn over the abdominal region. For each ROI, the total photon flux was calculated and used as primary readout for quantification of cell survival.

For MRI, one representative mouse from each group (3,000 and 6,000 MCs containing cells) was imaged at day 28 using a 9.4-T Bruker horizontal bore magnet. 2-D T2-weighted spin echo (SE) images were obtained using a slice thickness of $0.8 \mathrm{~mm}$ and the following parameters: repetition time $(\mathrm{TR})=1,500 \mathrm{~ms}$, echo time $(\mathrm{TE})=15 \mathrm{~ms}$, field of view $(\mathrm{FOV})=2.6 \times 2.6 \mathrm{~cm}$, and matrix $=172 \times 172$. T2*-weighted images were also obtained using a TR $=$ $500 \mathrm{~ms}, \mathrm{TE}=6 \mathrm{~ms}$, flip angle $=45^{\circ}, \mathrm{FOV}=3 \times 3 \mathrm{~cm}$, and matrix $=172 \times 172$.

\section{RESULTS}

\section{In Vitro Studies}

MCs were found to be uniform in size with a diameter of approximately $450 \mu \mathrm{m}$ (Fig. 1). The preparation appeared brown in color as a result of the coencapsulation of Feridex ${ }^{\circledR}$. Cells appeared to be homogeneously

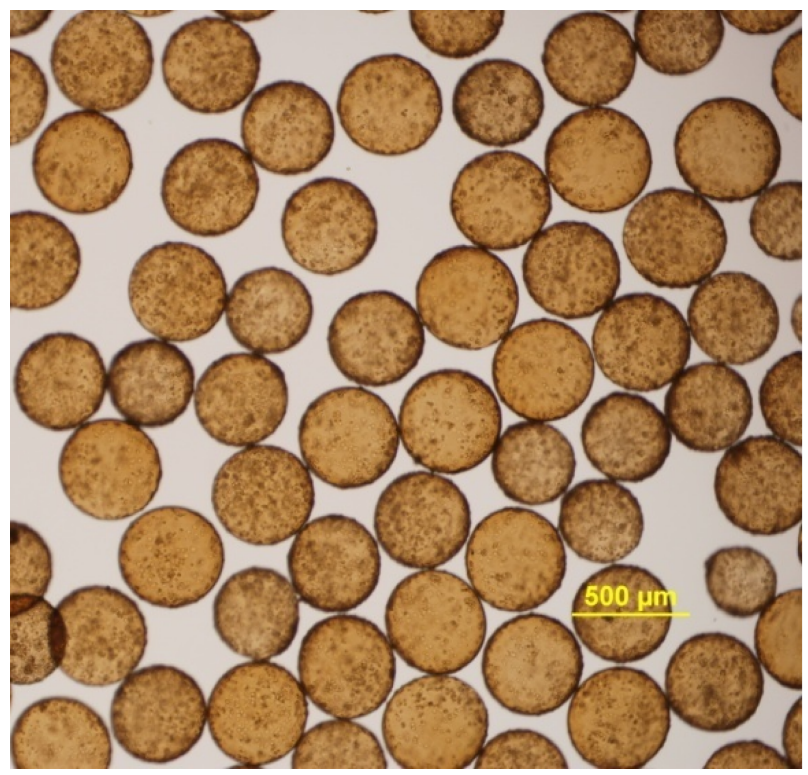

Figure 1. Light microscopic image of magnetoencapsulated HepG2 hepatocytes. Capsules measured $450 \mu \mathrm{m}$ in diameter, contained around 1,000 cells each, and have a brownish appearance that originated from the encapsulated iron oxide. Scale bar: $500 \mu \mathrm{m}$. 
A

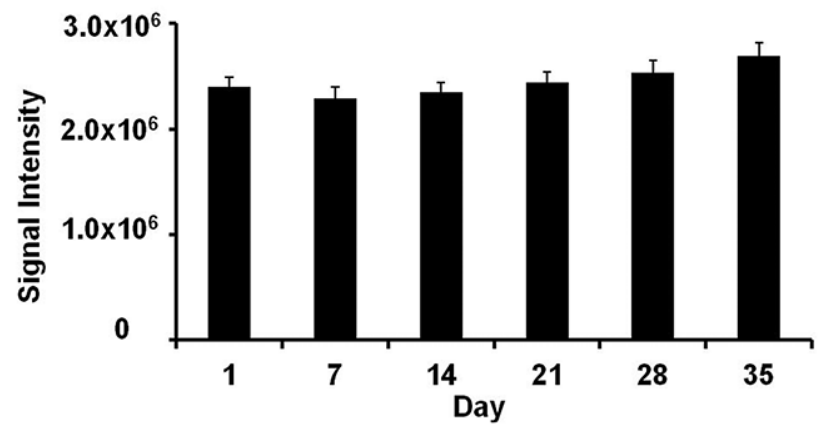

C

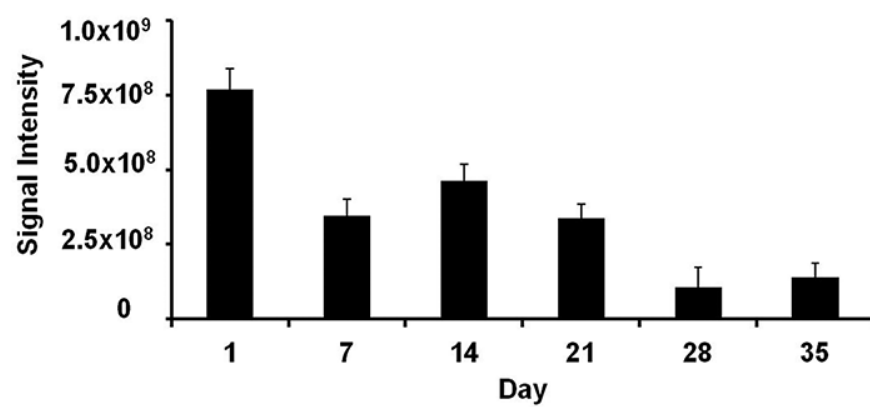

B

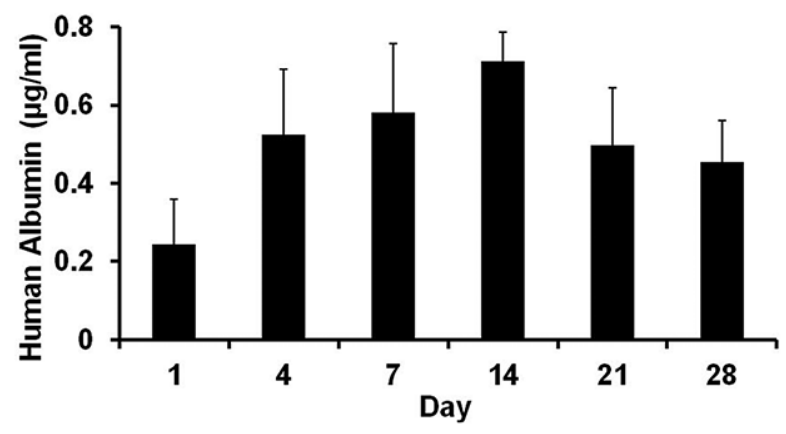

D

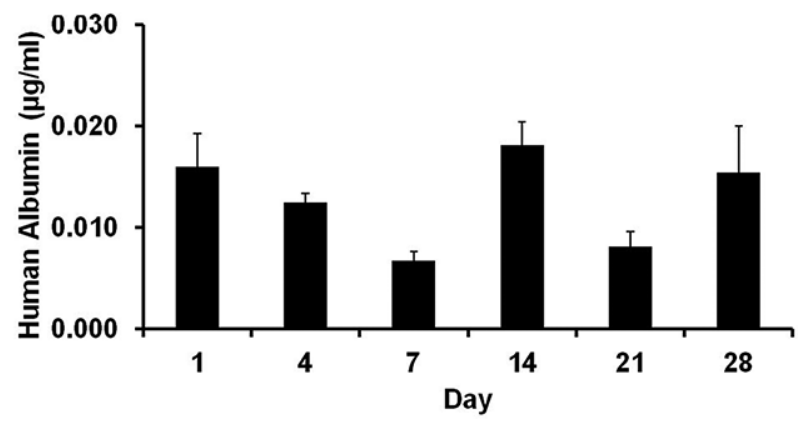

Figure 2. Bioluminescence signal intensity $(\mathrm{A}, \mathrm{C})$ and human albumin secretion $(\mathrm{B}, \mathrm{D})$ of naked $(\mathrm{A}, \mathrm{B})$ and magnetoencapsulated $(\mathrm{C}, \mathrm{D})$ cells in vitro. Cell densities were $1 \times 10^{4}$ cells and $1 \times 10^{5}$ cells per well, respectively.

encapsulated. The cell viability in vitro was determined by BLI (Fig. 2). The BLI signal was found to remain constant for naked hepatocytes throughout the 5-week period (Fig. 2A). For magnetoencapsulated cells, the initial BLI signal was much higher, caused by the $10 \times$ higher cell concentration, with a gradual decrease over time (Fig. 2C). Both naked and encapsulated hepatocytes continued to secrete albumin over a time period of
1 month (Fig. 2B and D). Human albumin production in vitro, as detected by ELISA, was in the range of about $0.4-0.7 \mu \mathrm{g} / \mathrm{ml}$ for naked cells and about $0.01-0.02 \mu \mathrm{g} /$ $\mathrm{ml}$ for encapsulated cells.

\section{In Vivo Mouse Studies}

Following intraperitoneal transplantation, naked human hepatocytes were found to rapidly die within the first days

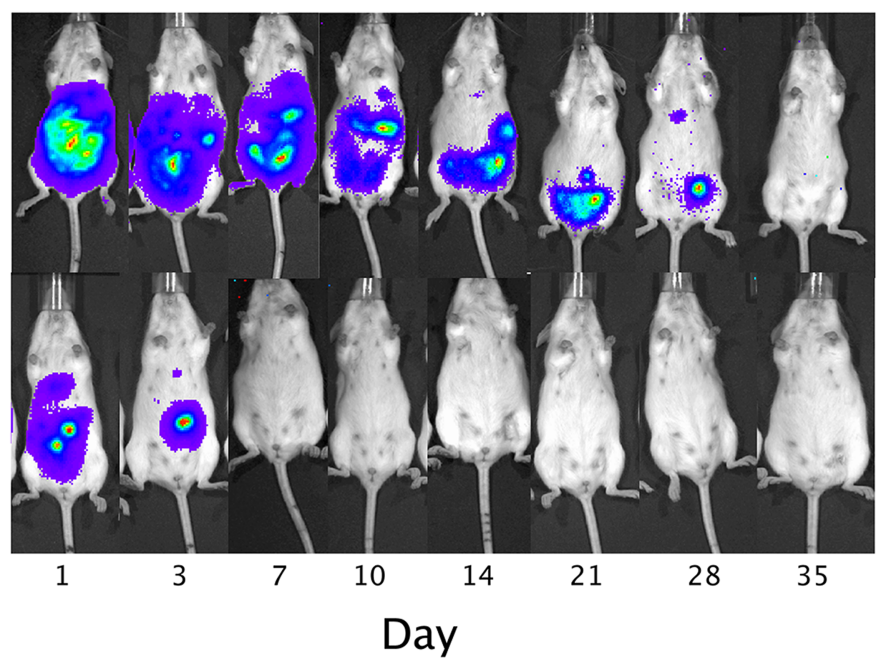

Figure 3. Representative bioluminescence images of a mouse transplanted intraperitoneally with 6,000 magnetocapsules (MCs; $1 \times 10^{3}$ cells per capsule, top) or $7.5 \times 10^{6}$ naked hepatocytes (bottom). 


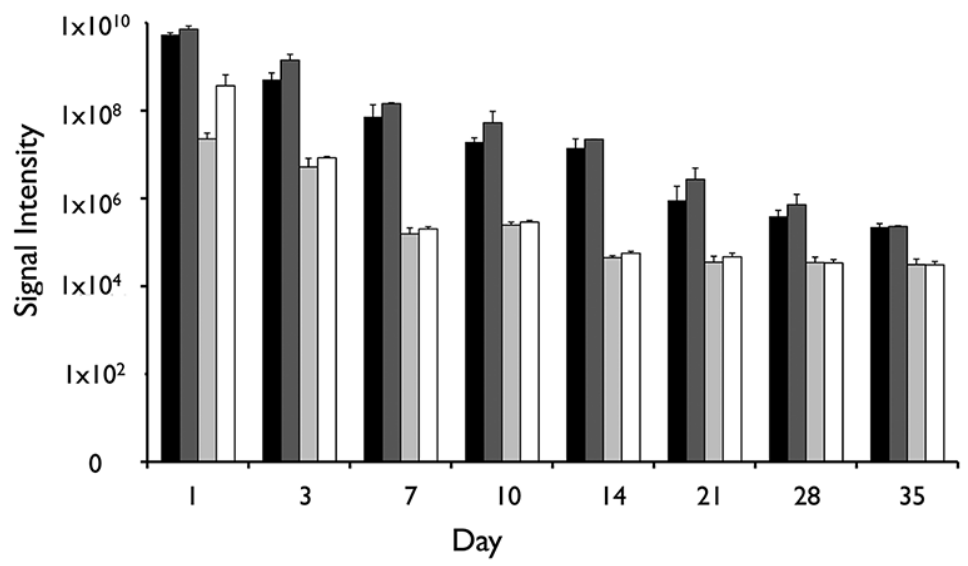

Figure 4. Total in vivo bioluminescent imaging (BLI) radiance levels over a period of 5 weeks for mice transplanted with $3 \times 10^{6}$ magnetoencapsulated cells (black bars), $6 \times 10^{6}$ magnetoencapsulated cells (dark gray bars), $3.75 \times 10^{6}$ naked cells (light gray bars), or $7.5 \times 10^{6}$ naked cells (white bars).

of transplantation (Fig. 3). In contrast, although the signal gradually decreased over time, the survival of magnetoencapsulated cells was significantly longer $(p<0.05$ for all time points, two-tailed Student's $t$ test), with the BLI signal persisting for about 4 weeks. The BLI signal from human hepatocytes was proportional to the amount of transplanted cells (Fig. 4) and corresponded to the in vivo human albumin production. At day 3, detectable albumin levels could only be seen for magnetoencapsulated cells, which lasted until day 7 for the higher amount of encapsulated cells (Fig. 5). The maximum plasma levels of human albumin were found to be on day 1 , with values of 9.34 and $24.16 \mu \mathrm{g} / \mathrm{ml}$ of human albumin for $3 \times 10^{6}$ and $6 \times 10^{6}$ magnetoencapsulated cells, respectively.

\section{MR Imaging}

Following intraperitoneal transplantation, MCs could be seen clearly throughout the peritoneal cavity (Fig. 6). The

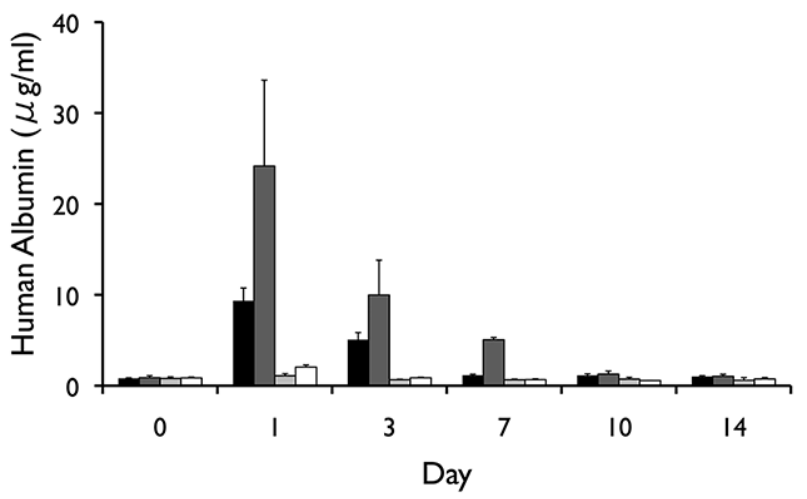

Figure 5. In vivo human albumin levels over a period of 5 weeks for mice transplanted with $3 \times 10^{6}$ magnetoencapsulated cells (black bars), $6 \times 10^{6}$ magnetoencapsulated cells (dark gray bars), $3.75 \times 10^{6}$ naked cells (light gray bars), or $7.5 \times 10^{6}$ naked cells (white bars).
SPIO-induced hypointensities were particularly pronounced on the $\mathrm{T} 2 *$-weighted images, as expected given that this imaging sequence is much more sensitive to the magnetic field inhomogeneities induced by the magnetocapsules.

\section{DISCUSSION}

In this study, we investigated the in vitro and in vivo functionality of xenografted human hepatocytes, which were embedded within magnetocapsules that are MR visible. As it has been previously reported that alginate-polyL-lysine-alginate (APLLA) capsules may cause fibrosis (35), possibly as a result from exposure of host tissue to poly-L-lysine (PLL)-derived cationic lysine residue that branches out into the outer layer of alginate $(33,38)$, we decided to use protamine sulfate as a polycation to crosslink alginate capsules instead. Protamine sulfate is a clinical grade antiheparin drug that has been reported to have less toxicity over other cationic transfection agents (34) and has been used in conjunction with Feridex ${ }^{\circledR}$ to render cells magnetic for MRI cell tracking studies (1).

In vitro, magnetoencapsulated human hepatocytes secreted lower levels of albumin as compared to naked hepatocytes, but the secretion was stable over the time period studied. The occurrence of a lower, steady production of albumin for encapsulated, immortalized human hepatocytes as compared to naked cells has previously been reported elsewhere (21). However, following xenogeneic transplantation of the encapsulated hepatocytes in a mouse model of FLF, the study by Mai et al. (21) did not report on the secreted albumin levels in vivo. Others have successfully encapsulated (xenografted) hepatocytes for treatment of acute liver failure $(15,22,30,44)$ and hepatectomy (42), but the exact time course of in vivo cell survival is unknown. In two studies, based on end-point histological observations, encapsulated hepatocytes injected intraperitoneally were reported to survive up to 14-35 days 


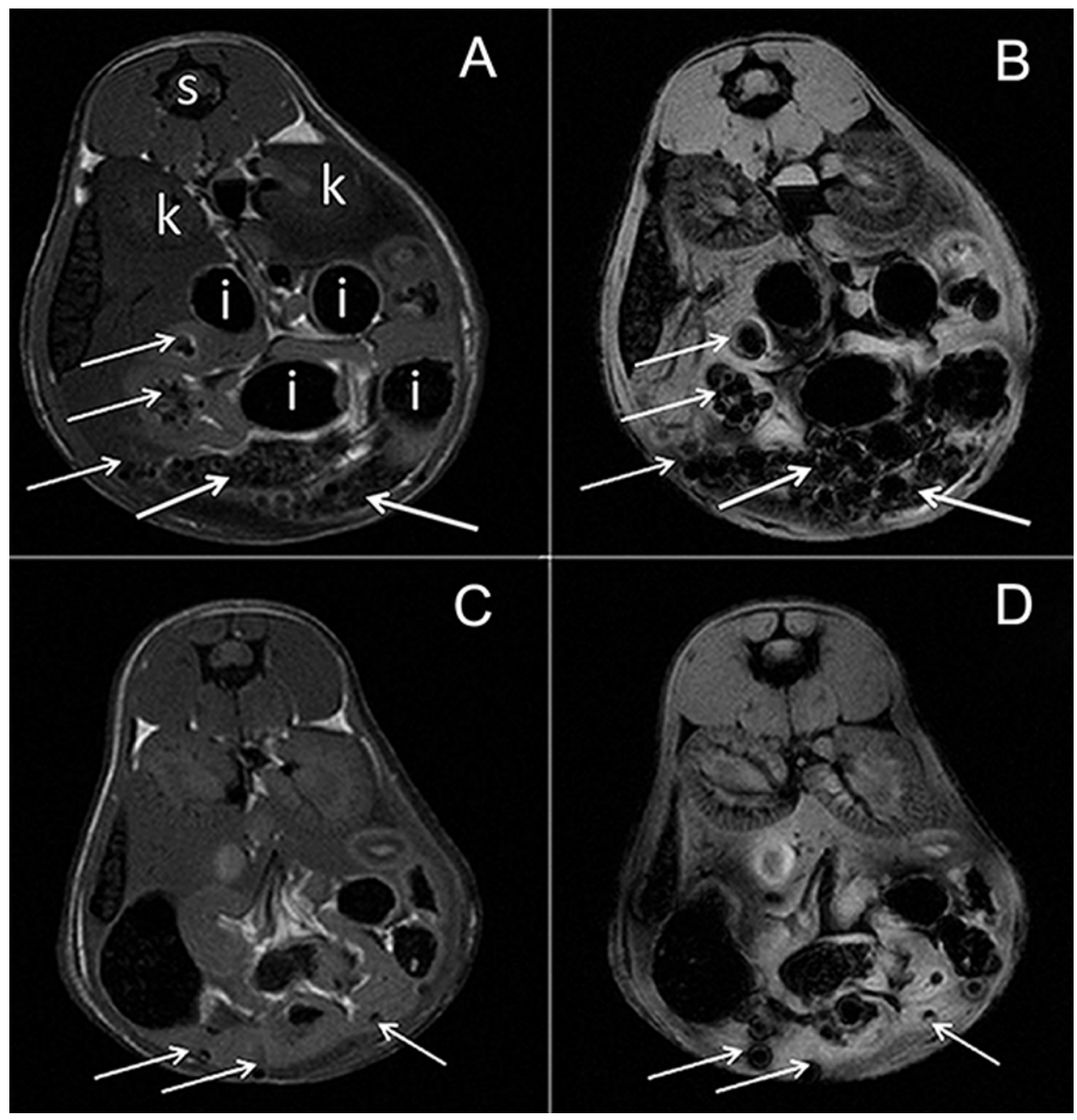

Figure 6. Magnetic resonance (MR) images of the peritoneal cavity of mice transplanted with 6,000 (A, B) or 3,000 (C, D) magnetocapsules. Shown are T2- (A, C) and T2*- (B,D) weighted images. MCs can be seen as dispersed hypointensities throughout the peritoneal cavity at the single capsule level (arrows). s, spinal cord; k, kidney; i, intestinal tract (hypointense containing stool and air).

$(3,8,37)$. In our study, we assessed the time course of survival noninvasively using BLI. This imaging technique, based on the conversion of luciferin by luciferase under emission of photons, has previously been used to determine the survival of encapsulated kidney epithelial cells (18), fibroblasts (39), and pancreatic islet cells (29).

We found that, in vitro, both naked cells and encapsulated cells survived for a 5-week period in culture. In vivo, naked hepatocytes did not survive for more than a few days, while magnetoencapsulated hepatocytes survived for a full 4 weeks. In vivo albumin production by naked cells was negligible, even for the first few days when they were still alive. Encapsulated cells, in contrast, exhibited sustained secretion levels in a cell-dose-dependent manner for about 1 week post-transplantation. The reason for this much more rapid decline in albumin secretion as compared to the relative number of surviving cells is not known, but the continued production of albumin for 7 days may be sufficiently long enough to enable the use of encapsulated hepatocyte cell therapy as a temporary bridge until a suitable liver transplant is available.

Previously, hepatocytes have been labeled with SPIO in order to be detected with MRI $(27,31)$. For example, Morgul et al. (24) used Tat-peptide-modified superparamagnetic nanoparticles to label human hepatocytes, which were clearly detectable on a 3.0-T clinical MR scanner. MR labeling of cells has now entered the clinic for monitoring cell transplantation and allows real-time assessment of the initial cell engraftment as well as the use of MR-compatible catheters for real-time MR-guided injection (10). In order to visualize alginate microcapsules, exogenous contrast agents have been coencapsulated (5) for visualization by $\operatorname{MR}(2,4,7,16)$, ultrasound $(2,7,16)$, or X-ray/computed tomography (CT) imaging $(2,6,7,16)$. 
Rather than labeling hepatocytes directly, we embedded SPIO within the hydrogel of the alginate capsule in order to make encapsulated hepatocytes that are MR visible. Indeed, magnetocapsules could be detected on the single capsule level, which suggest that MR monitoring of engraftment and cell injection is indeed possible.

In summary, we have synthesized magnetocapsules as a novel entity for immunoprotecting hepatocytes while simultaneously allowing MR imaging. Magnetoencapsulated hepatocytes showed a dramatically improved survival following xenogeneic transplantation and secrete albumin in vivo for at least 1 week postgrafting. The present results are directly relevant to ongoing efforts in developing encapsulated cell therapy for treatment of acute liver disease.

ACKNOWLEDGMENTS: This study was supported by RO1 EB007825 and U54 CA151838. Dr. Bulte is a paid consultant for MRI Interventions, Inc. This arrangement has been approved by The Johns Hopkins University in accordance with its Conflict of Interest policies. Dr. Arepally is also a paid consultant for MRI Interventions, Inc., and founder of Surefire Medical, Inc. We are grateful to Brad Barnett for his initial discussions and advice on magnetoencapsulation.

\section{REFERENCES}

1. Arbab, A. S.; Yocum, G. T.; Rad, A. M.; Khakoo, A. Y.; Fellowes, V.; Read, E. J.; Frank, J. A. Labeling of cells with ferumoxides-protamine sulfate complexes does not inhibit function or differentiation capacity of hematopoietic or mesenchymal stem cells. NMR Biomed. 18:553-559; 2005.

2. Arifin, D. R.; Long, C. M.; Gilad, A. A.; Alric, C.; Roux, S.; Tillement, O.; Link, T. W.; Arepally, A.; Bulte, J. W. Trimodal gadolinium-gold microcapsules containing pancreatic islet cells restore normoglycemia in diabetic mice and can be tracked by using US, CT, and positive-contrast MR imaging. Radiology 260:790-798; 2011.

3. Baldini, E.; Cursio, R.; De Sousa, G.; Margara, A.; Honiger, J.; Saint-Paul, M. C.; Bayer, P.; Raimondi, V.; Rahmani, R.; Mouiel, J.; Gugenheim, J. Peritoneal implantation of cryopreserved encapsulated porcine hepatocytes in rats without immunosuppression: Viability and function. Transplant. Proc. 40:2049-2052; 2008.

4. Barnett, B. P.; Arepally, A.; Karmarkar, P. V.; Qian, D.; Gilson, W. D.; Walczak, P.; Howland, V.; Lawler, L.; Lauzon, C.; Stuber, Kraitchman, D. L.; Bulte, J. W. Magnetic resonance-guided, real-time targeted delivery and imaging of magnetocapsules immunoprotecting pancreatic islet cells. Nat. Med. 13:986-991; 2007.

5. Barnett, B. P.; Arepally, A.; Stuber, M.; Arifin, D. R.; Kraitchman, D. L.; Bulte, J. W. Synthesis of magnetic resonance-, X-ray- and ultrasound-visible alginate microcapsules for immunoisolation and noninvasive imaging of cellular therapeutics. Nat. Prot. 6:1142-1151; 2011.

6. Barnett, B. P.; Kraitchman, D. L.; Lauzon, C.; Magee, C. A.; Walczak, P.; Gilson, W. D.; Arepally, A.; Bulte, J. W. Radiopaque alginate microcapsules for X-ray visualization and immunoprotection of cellular therapeutics. Mol. Pharm. 3:531-538; 2006.

7. Barnett, B. P.; Ruiz-Cabello, J.; Hota, P.; Liddell, R.; Walczak, P.; Howland, V.; Chacko, V. P.; Kraitchman, D. L.; Arepally,
A.; Bulte, J. W. Fluorocapsules for improved function, immunoprotection, and visualization of cellular therapeutics with MR, US, and CT imaging. Radiology 258:182-191; 2011.

8. Benoist, S.; Sarkis, R.; Barbu, V.; Honiger, J.; Baudrimont, M.; Lakehal, F.; Becquemont, L.; Delelo, R.; Housset, C.; Balladur, P.; Capeau, J; Nordlinger, B. Survival and functions of encapsulated porcine hepatocytes after allotransplantation or xenotransplantation without immunosuppression. Surgery 129:606-616; 2001.

9. Broering, D. C.; Sterneck, M.; Rogiers, X. Living donor liver transplantation. J. Hepatol. 38 Suppl 1:S119-135; 2003.

10. Bulte, J. W. In vivo MRI cell tracking: Clinical studies. AJR Am. J. Roentgenol. 193:314-325; 2009.

11. Dhawan, A.; Puppi, J.; Hughes, R. D.; Mitry, R. R. Human hepatocyte transplantation: Current experience and future challenges. Nat. Rev. Gastroenterol. Hepatol. 7:288-298; 2010.

12. Dhawan, A.; Strom, S. C.; Sokal, E.; Fox, I. J. Human hepatocyte transplantation. Meth. Mol. Biol. 640:525-534; 2010.

13. Hoofnagle, J. H.; Carithers, Jr., R. L.; Shapiro, C.; Ascher, N. Fulminant hepatic failure: Summary of a workshop. Hepatology 21:240-252; 1995.

14. Ito, M.; Nagata, H.; Miyakawa, S.; Fox, I. J. Review of hepatocyte transplantation. J. Hepatobiliary Pancreat. Surgery 16:97-100; 2009.

15. Kanai, N.; Hagihara, M.; Nagamachi, Y.; Tsuji, K. Beneficial effects of immunoisolated fetal and neonatal pig liver fragments on acute liver failure in a large animal. Cell Transplant. 8:413-417; 1999.

16. Kim, J.; Arifin, D. R.; Muja, N.; Kim, T.; Gilad, A. A.; Kim, H.; Arepally, A.; Hyeon, T.; Bulte, J. W. Multifunctional capsule-in-capsules for immunoprotection and trimodal imaging. Angew. Chem. Int. Ed. Engl. 50:2317-2321; 2011.

17. Lee, W. M. Acute liver failure. N. Engl. J. Med. 329:1862$1872 ; 1993$.

18. Li, A. A.; Hou, D. Y.; Shen, F.; Seidlitz, E. P.; Potter, M. A. Luciferase therapeutic microcapsules for gene therapy. Artif. Cells Blood Substit. Immobil. Biotechnol. 37:235-244; 2009.

19. Link, T. W.; Woodrum, D.; Gilson, W. D.; Pan, L.; Qian, D.; Kraitchman, D. L.; Bulte, J. W.; Arepally, A.; Weiss, C. R. MR-guided portal vein delivery and monitoring of magnetocapsules: Assessment of physiologic effects on the liver. J. Vasc. Interv. Radiol. 22:1335-1340; 2011.

20. Liu, J. P.; Gluud, L. L.; Als-Nielsen, B.; Gluud, C. Artificial and bioartificial support systems for liver failure. Cochrane Database Syst. Rev. 2004(1):CD003628; 2004.

21. Mai, G.; Nguyen, T. H.; Morel, P.; Mei, J.; Andres, A.; Bosco, D.; Baertschiger, R.; Toso, C.; Berney, T.; Majno P.; Mentha, G.; Trono, D.; Buhler, L. H. Treatment of fulminant liver failure by transplantation of microencapsulated primary or immortalized xenogeneic hepatocytes. Xenotransplant. 12:457-464; 2005.

22. Mei, J.; Sgroi, A.; Mai, G.; Baertschiger, R.; GonelleGispert, C.; Serre-Beinier, V.; Morel, P.; Buhler, L. H. Improved survival of fulminant liver failure by transplantation of microencapsulated cryopreserved porcine hepatocytes in mice. Cell Transplant. 18:101-110; 2009.

23. Mills, P. H.; Hitchens, T. K.; Foley, L. M.; Link, T.; Ye, Q.; Weiss, C. R.; Thompson, J. D.; Gilson, W. D.; Arepally, A.; Melick, J. A.; Kochanek, P. M.; Ho, C.; Bulte, J. W.; Ahrens, E. T. Automated detection and characterization of SPIO-labeled cells and capsules using magnetic field perturbations. Magn. Reson. Med. 67:278-289; 2012.

24. Morgul, M. H.; Raschzok, N.; Schwartlander, R.; Vondran, F. W.; Michel, R.; Stelter, L.; Pinkernelle, J.; Jordan, A.; 
Teichgraber, U.; Sauer, I. M. Tracking of primary human hepatocytes with clinical MRI: Initial results with Tatpeptide modified superparamagnetic iron oxide particles. Int. J. Artif. Organs 31:252-257; 2008.

25. Orive, G.; Hernandez, R. M.; Gascon, A. R.; Calafiore, R.; Chang, T. M.; De Vos, P.; Hortelano, G.; Hunkeler, D.; Lacik, I.; Shapiro, A. M.; Pedraz, J. L. Cell encapsulation: Promise and progress. Nat. Med. 9:104-107; 2003.

26. Pappas, S. C.; Rouch, D. A.; Stevens, L. H. New techniques for liver transplantation: Reduced-size, split-liver, living-related and auxiliary liver transplantation. Scand. J. Gastroenterol. Suppl. 208:97-100; 1995.

27. Puppi, J.; Mitry, R. R.; Modo, M.; Dhawan, A.; Raja, K.; Hughes, R. D. Use of a clinically approved iron oxide MRI contrast agent to label human hepatocytes. Cell Transplant. 20:963-975; 2011.

28. Puppi, J.; Strom, S. C.; Hughes, R. D.; Bansal, S.; Castell, J. V.; Dagher, I.; Ellis, E. C.; Nowak, G.; Ericzon, B. G.; Fox, I. J.; Gomez-Lechon, M. J.; Guha, C.; Gupta, S.; Mitry, R. R.; Ohashi, K.; Ott, M.; Reid, L. M.; Roy-Chowdhury, J.; Sokal, E.; Weber, A.; Dhawan, A. Improving the techniques for human hepatocyte transplantation: Report from a consensus meeting in London. Cell Transplant. 21:1-10; 2012.

29. Roth, D. J.; Jansen, E. D.; Powers, A. C.; Wang, T. G. A novel method of monitoring response to islet transplantation: Bioluminescent imaging of an NF-kB transgenic mouse model. Transplantation 81:1185-1190; 2006.

30. Sgroi, A.; Mai, G.; Morel, P.; Baertschiger, R. M.; GonelleGispert, C.; Serre-Beinier, V.; Buhler, L. H. Transplantation of encapsulated hepatocytes during acute liver failure improves survival without stimulating native liver regeneration. Cell Transplant. 20:1791-1803; 2011.

31. Shapiro, E. M.; Sharer, K.; Skrtic, S.; Koretsky, A. P. In vivo detection of single cells by MRI. Magn. Reson. Med. 55:242-249; 2006.

32. Soltys, K. A.; Soto-Gutierrez, A.; Nagaya, M.; Baskin, K. M.; Deutsch, M.; Ito, R.; Shneider, B. L.; Squires, R.; Vockley, J.; Guha, C.; Roy-Chowdhury, J.; Strom, S. C.; Platt, J. L.; Fox, I. J. Barriers to the successful treatment of liver disease by hepatocyte transplantation. J. Hepatol. 53:769-774; 2010.

33. Soon-Shiong, P.; Heintz, R. E. Insulin independence in a type 1 diabetic patient after encapsulated islet transplantation. Lancet 343:950-951; 1994.
34. Sorgi, F. L.; Bhattacharya, S.; Huang, L. Protamine sulfate enhances lipid-mediated gene transfer. Gene Ther. 4:961968; 1997.

35. Strand, B. L.; Ryan, L.; Veld, P. I.; Kulseng, B.; Rokstad, A. M.; Skjak-Braek, G.; Espevik, T. Poly-L-lysine induces fibrosis on alginate microcapsules via the induction of cytokines. Cell Transplant. 10:263-275; 2001.

36. Strom, S. C.; Fisher, R. A.; Thompson, M. T.; Sanyal, A. J.; Cole, P. E.; Ham, J. M.; Posner, M. P. Hepatocyte transplantation as a bridge to orthotopic liver transplantation in terminal liver failure. Transplantation 63:559-569; 1997.

37. Sun, A. M.; Cai, Z.; Shi, Z.; Ma, F.; O'Shea, G. M. Microencapsulated hepatocytes: An in vitro and in vivo study. Biomater. Artif. Cells Artif. Organs 15:483-496; 1987.

38. Tam, S. K.; de Haan, B. J.; Faas, M. M.; Halle, J. P.; Yahia, L.; de Vos, P. Adsorption of human immunoglobulin to implantable alginate-poly-L-lysine microcapsules: Effect of microcapsule composition. J. Biomed. Mater. Res. A 89:609-615; 2009.

39. Tarantal, A. F.; Lee, C. C.; Itkin-Ansari, P. Real-time bioluminescence imaging of macroencapsulated fibroblasts reveals allograft protection in rhesus monkeys (Macaca mulatta). Transplantation 88:38-41; 2009.

40. Toso, C.; Oberholzer, J.; Ceausoglu, I.; Ris, F.; Rochat, B.; Rehor, A.; Bucher, P.; Wandrey, C.; Schuldt, U.; Belenger, J.; Bosco, D.; Morel, P.; Hunkeler, D. Intra-portal injection of 400-micron microcapsules in a large-animal model. Transpl. Int. 16:405-410; 2003.

41. Tuch, B. E.; Keogh, G. W.; Williams, L. J.; Wu, W.; Foster, J. L.; Vaithilingam, V.; Philips, R. Safety and viability of microencapsulated human islets transplanted into diabetic humans. Diabetes Care 32:1887-1889; 2009.

42. Umehara, Y.; Hakamada, K.; Seino, K.; Aoki, K.; Toyoki, Y.; Sasaki, M. Improved survival and ammonia metabolism by intraperitoneal transplantation of microencapsulated hepatocytes in totally hepatectomized rats. Surgery 130:513-520; 2001.

43. van de Kerkhove, M. P.; Hoekstra, R.; Chamuleau, R. A.; van Gulik, T. M. Clinical application of bioartificial liver support systems. Ann. Surg. 240:216-230; 2004.

44. Zheng, M. H.; Lin, H. L.; Qiu, L. X.; Cui, Y. L.; Sun, Q. F.; Chen, Y. P. Mixed microencapsulation of rat primary hepatocytes and Sertoli cells improves the metabolic function in a D-galactosamine and lipopolysaccharide-induced rat model of acute liver failure. Cytotherapy 11:326-329; 2009. 